\title{
A TOPSIS-based approach for wind turbines ranking with negative performance ratings and different weighting strategies
}

\author{
Dănuț Zahariea ${ }^{1, *}$, Dorin Emil Husaru ${ }^{1}$, and Mihai Silviu Pavă ${ }^{1}$ \\ 1"Gheorghe Asachi” Technical University of Iasi, D. Mangeron No. 67, 700571, Iasi, Romania
}

\begin{abstract}
This paper presents an application of TOPSIS (Technique for Order of Preference by Similarity to Ideal Solution) multi-dimensional criteria decision-making method for a case study related with a wind turbine based on-grid power supply system with negative performance ratings and different weighting strategies. Two wind turbines (XZ and XL) are comparatively analysed with respect to a power supply system for an industrial consumer and a given site. The site wind potential has been obtained from NASA Surface meteorology and Solar Energy database. The on-grid power supply system has been modelled and simulated using HOMER Pro software. Ten attributes have been considered: five technical criteria, four financial criteria and one environmental criterion. Eleven different weighting strategies have been considered. From all these weighting strategies, the $\mathrm{XZ}$ wind turbine has been selected in 8 cases while the XL wind turbine has been selected in 2 cases. For two particular weighting strategies, the most suitable alternative (XZ) coincides with the ideal solution, while the other alternative (XL) coincides with the negative ideal solution.
\end{abstract}

\section{Introduction}

Very often, during the process of renewable projects development, particularly for wind power projects, there are situations which involve choosing one alternative from several possible, by comparing the alternatives under a certain set of weights. One of the most important such situations is the selection of the most suitable wind turbine for a certain site [1-3].

The selection of the most suitable alternative is generally based on multi-criteria decision making (MCDM) analysis. The main steps of an MCDM analysis are: selecting the alternatives, defining the criteria which will be used for comparing the alternatives, defining the specific weighting strategy of criteria evaluation by importance, computing the rank order of the alternatives and obtaining of the most preferred alternative by using a specific MCDM method [4, 5]. The most important MCDM methods are [4, 5]: weighted sum method [2]; weighted product method [6]; analytical hierarchy process [1]; analytical network process; fuzzy analytical network process [3]; interpretive structural modelling [3]; technique for order of preference by similarity to ideal solution; elimination and choice expressing reality.

The weighted product method has been used in [6] for selection of the most suitable wind turbine between two alternatives, based on a single weighting strategy and nine criteria, of which five are technical criteria (annual energy production, wind turbine capacity factor, renewable fraction, grid purchase and grid sales) and four are financial criteria (net present cost, cost of energy, initial investment and simple payback). At the beginning of that study, the $10^{\text {th }}$ criterion (environmental type) has been also proposed: $\mathrm{CO}_{2}$ emission. According with the HOMER calculations, for an on-grid power supply system, the $\mathrm{CO}_{2}$ emission [t/year] is calculated with the formula [7]:

$$
\mathrm{CO}_{2}=\left(G_{p}-G_{s}\right) \cdot f_{\mathrm{CO}_{2}}
$$

where $G_{p}[\mathrm{kWh} /$ year $]$ and $G_{s}[\mathrm{kWh} /$ year $]$ are the total grid purchases and the total grid sales, and $f_{\mathrm{CO}_{2}}[\mathrm{t} / \mathrm{kWh}]$ is the $\mathrm{CO}_{2}$ emission factor. If $G_{p}<G_{s}$, the grid-related emission of $\mathrm{CO}_{2}$ is negative.

During that analysis, this particular situation has been noticed, and negative values of the $10^{\text {th }}$ criterion have been obtained. As a consequence of the fact that the authors did not find a way to handle these negative values with weighted product method, the $10^{\text {th }}$ criterion has been removed from the criteria list and the decision process has been made based only on the rest of nine criteria. But the problem remains: handling negative performance ratings in the general context of MCDM analysis.

In this paper a similar wind power project will be presented, with the same two wind turbines as alternatives, but for a different site and a different consumer. Moreover, in this case study the criteria list will includes also the $10^{\text {th }}$ criterion, but a different MCDM method will be used: the TOPSIS method [5].

One sensitive parameter related with the consumer will be defined. For some values of this sensitive parameter, the $10^{\text {th }}$ criterion will have both negative values, or both positive values, or, finally, one negative value and the other, positive value.

To analyse the influence of weighting strategy, eleven weighting strategies will be considered: five strategies based on technical, financial and environmental criteria; two strategies based only on technical and financial criteria, two strategies based only on financial and

\footnotetext{
* Corresponding author: dzahariea@yahoo.com
} 
environmental criteria, and two strategies based only on technical and environmental criteria.

\section{Case study}

Let us consider a power supply system composed by a wind turbine on-grid connected which will supply electricity for a single consumer. Considering the proposed wind turbine site, the wind resources will be obtained. Two different wind turbines will be analysed for the same site in order to supply electricity for the same consumer: XZERES $10 \mathrm{~kW}$ (XZ) [8], and Bergey Excel $10 \mathrm{~kW}$ (XL) [9]. The computations have been performed using HOMER Pro software (Hybrid Optimization of Multiple Energy Resources) [7].

\subsection{Site location and wind resources}

The wind turbine site is located in Denmark, on the North Sea shore, between Hamborg and Febbbersted, at the coordinates 57.1162556 and 8.6622306. The wind and temperature resources for the proposed site have been obtained from NASA Surface meteorology and Solar Energy database (NASA Langley Research Centre Atmospheric Science Data Centre Surface meteorological and Solar Energy (SSE) web portal supported by the NASA LaRC POWER Project) [10].

The wind speed at $50 \mathrm{~m}$ height is presented in Figure 1. The maximum wind speed is $8.66 \mathrm{~m} / \mathrm{s}$ in January, while the minimum wind speed is $5.32 \mathrm{~m} / \mathrm{s}$ in June, and the annual average wind speed is $6.91 \mathrm{~m} / \mathrm{s}$. The reference wind speed for the proposed site is obtained at the reference height of $50 \mathrm{~m}$, while the standard hub height for both wind turbines is $24.4 \mathrm{~m}$ [8, 9]. For extrapolating the wind speed at the hub height, the wind speed logarithmic profile is used.

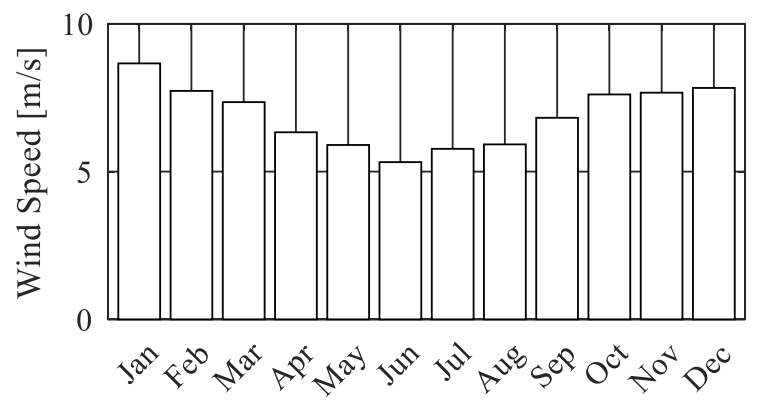

Fig. 1. Monthly average wind speed at $50 \mathrm{~m}$.

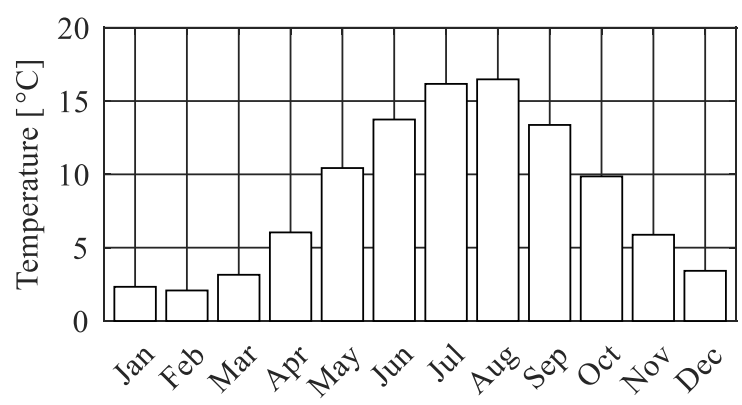

Fig. 2. Monthly average temperature.
The temperature for the selected site is presented in Figure 2. The maximum temperature is $16.48{ }^{\circ} \mathrm{C}$ in August, while the minimum temperature is $2.08{ }^{\circ} \mathrm{C}$ in February, the temperature range is $14.4^{\circ} \mathrm{C}$, and the annual average temperature is $8.58{ }^{\circ} \mathrm{C}$.

\subsection{Electric load}

Let us consider that the wind turbine on-grid connected power supply system will be used for supply electricity for an industrial consumer with a daily maximum primary load of $100 \mathrm{kWh} /$ day.

HOMER provide load profiles templates for different types of consumers: residential, commercial, industrial and community [7]. For this case study, the industrial load profile has been selected, the average load has been scaled to $100 \mathrm{kWh} /$ day and some random variability has been introduced by day-to-day and timestep parameters. In order to ensure a reliable electricity supply, despite variability in load and renewable power output, the operating reserve is considered in HOMER calculations by $10 \%$ of load in current time step, as well as by $50 \%$ of renewable output. In this way, the power supply system will be able to have enough spare operating capacity to serve a sudden $10 \%$ increase in the load, as well as a sudden $50 \%$ decrease in wind turbine output.

Under these circumstances, HOMER will obtain the consumer electric load which can be expressed, for example, by seasonal load profile presented in a box and whisker plot format in Figure 3.

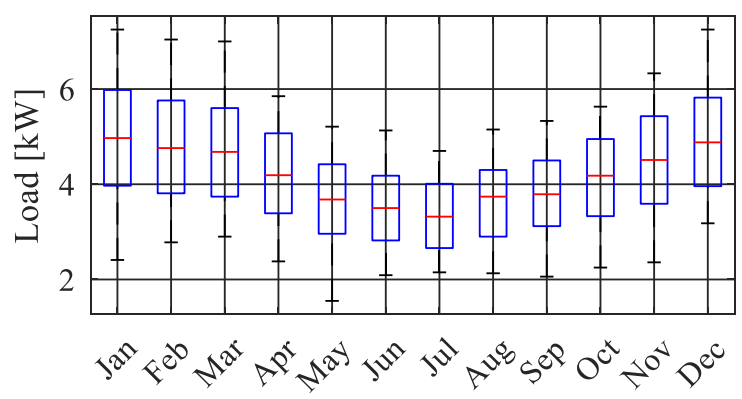

Fig. 3. Seasonal load profile.

The top and bottom lines correspond to the overall maximum and minimum for each month. The top and the bottom of the blue box correspond to the average daily maximum and minimum of all of the days in each month. Finally, the middle red lines correspond to the overall average for the whole month. Figure 3 shows the peak load of $7.25 \mathrm{~kW}$ for January and December while the computed average will be $4.17 \mathrm{~kW}$ with a load factor of 0.57 .

Let us consider that the industrial consumer will work at different production levels, defining in this way the consumer power load level as a sensitive parameter. Moreover, let us assume the following values for this sensitive parameter $\{60 ; 70 ; 80 ; 90 ; 100\} \%$ for which the daily average load will be $\{60 ; 70 ; 80 ; 90 ; 100\} \mathrm{kWh} /$ day, and the annual average load will be $\{21.9 ; 25.55 ; 29.2$; $32.85 ; 36.5\} \cdot 10^{3} \mathrm{kWh} /$ year. 


\subsection{On-grid power supply system}

The power supply systems are composed by the consumer, the grid, and the wind turbine (XZ or $\mathrm{XL}$ ), Figure 4, a). These two power supply systems will be comparatively analysed with respect to the reference power supply system, based only on the grid, Figure 4, b).

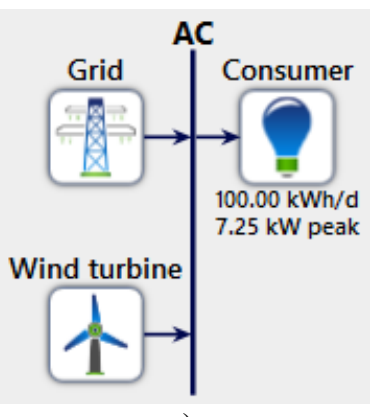

a)

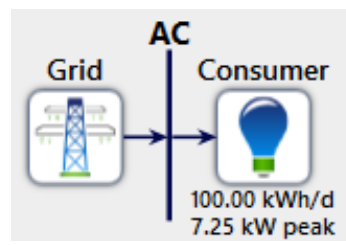

b)
Fig. 4. The power supply system.

For this case study, the principal characteristics of the power supply system are: 20 years lifetime; $8 \%$ nominal discount rate; $2 \%$ expected inflation rate; $0.28 € / \mathrm{kWh}$ grid power price; $0.2 € / \mathrm{kWh}$ grid sellback price; $25 € / \mathrm{tCO}_{2}$ carbon dioxide penalty. For Denmark, the electricity price, with all taxes included, has been obtained from EUROSTAT database, for non-household consumers in consumption band IB, $20 \mathrm{MWh} \div 500 \mathrm{MWh}$, for the $2^{\text {nd }}$ semester of 2017 [11], while the carbon dioxide penalty has been obtained from [12].

\subsection{Numerical results}

All parameters discussed above represent input data for a HOMER project file which has been calculated for each value of production level. In order to comparatively analyse the wind turbine power supply systems with respect to the reference case based only on the grid, three types of attributes have been considered and computed with HOMER software:

- Technical criteria, (T): T1: Annual Energy Production, AEP [kWh/year]; T2: Wind turbine capacity factor [\%]; T3: Renewable fraction [\%]; T4: Grid purchase [kWh/year]; T5: Grid sales [kWh/year].

- Financial criteria, (F): F1: Net Present Cost, NPC [€]; F2: Cost of Energy, COE [€]; F3: Initial investment $[€]$; F4: Simple payback [years].

- Environmental criteria, (E): E1: $\mathrm{CO}_{2}$ emissions [t/year].

Based on the HOMER calculations results, several comparative analyses will be presented. In Figure 5 and Figure 6 the comparatively analysis with respect to NPC and $\mathrm{COE}$ is presented. Both wind turbine-based power supply systems are placed in the white area, this means that both are feasible systems. Moreover, the XL wind turbine is the best option with respect to NPC and COE.

Different conclusion can be obtained if $\mathrm{CO}_{2}$ emissions (Figure 7) and grid purchase (Figure 8) criteria are considered: the best option is the $\mathrm{XZ}$ wind turbine.

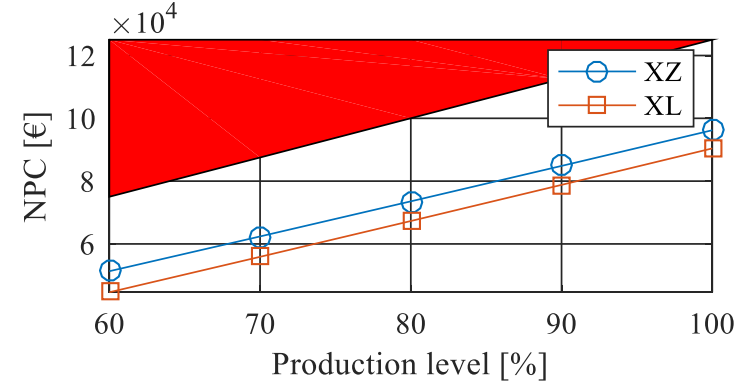

Fig. 5. Net present cost.

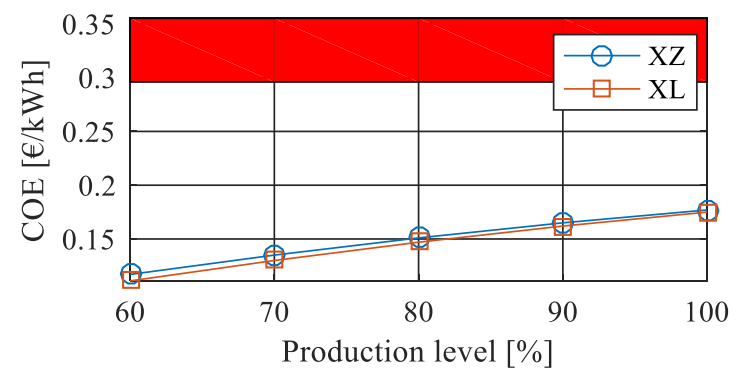

Fig. 6. Cost of energy.

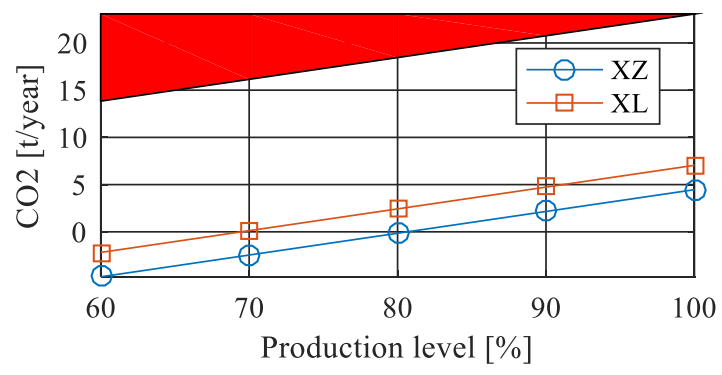

Fig. 7. $\mathrm{CO}_{2}$ emissions.

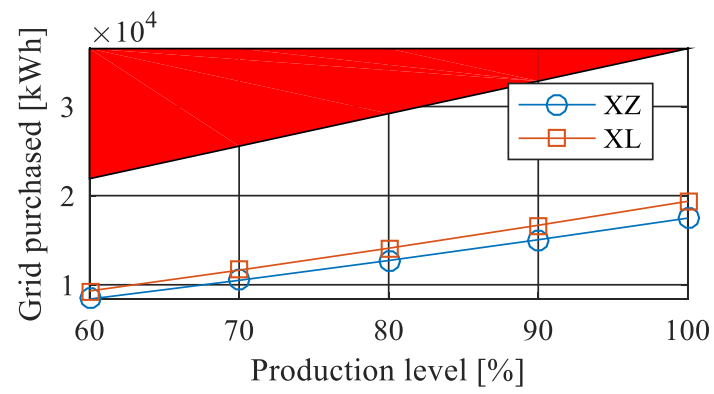

Fig. 8. Grid purchase.

The boundary between the white area (feasible systems) and the red area (prohibitive systems) for all figures presented above, represent the grid behaviour in terms of NPC (Figure 5), $\mathrm{COE}$ (Figure 6), $\mathrm{CO}_{2}$ emissions (Figure 7), and grid purchase (Figure 8). Both wind turbines define power supply systems which are better than the grid, but, unfortunately, only on these observations cannot decide upon the best option. If we consider the grid sales (Figure 9) and the renewable fraction (Figure 10), the best option is the $\mathrm{XZ}$ wind turbine. On the other hand, if we consider the simple payback criteria (Figure 11), the best option is the XL wind turbine, increasing the decision uncertainty. 


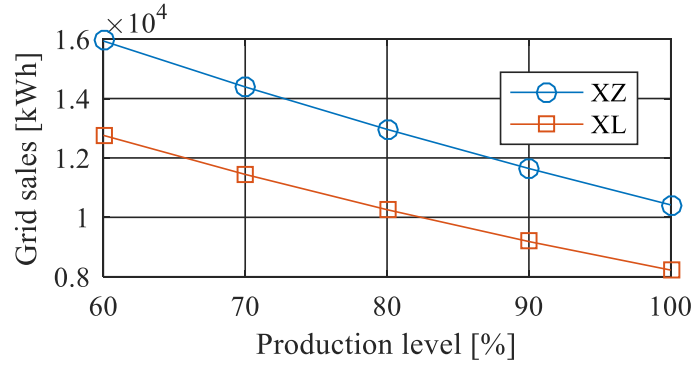

Fig. 9. Grid sales.

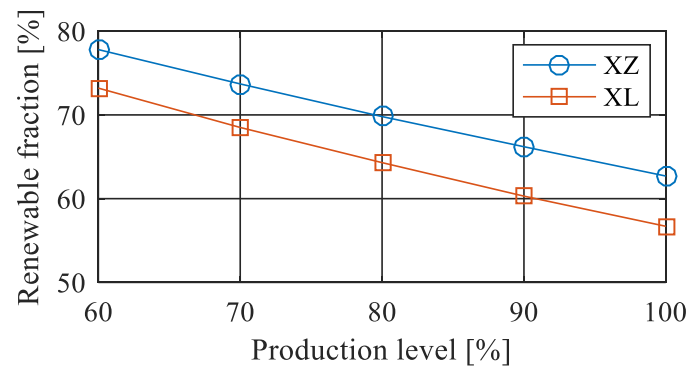

Fig. 10. Renewable fraction.

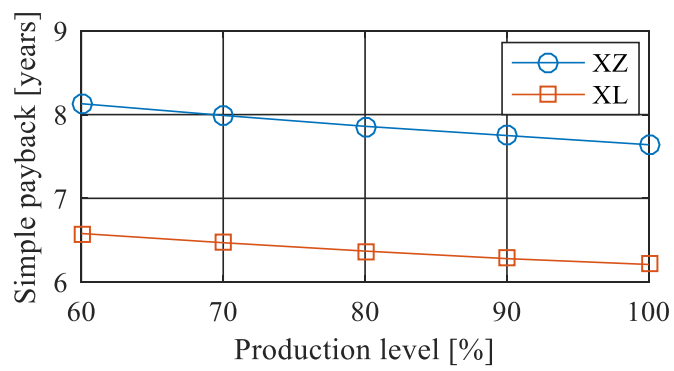

Fig. 11. Simple payback.

\section{TOPSIS method}

It is clear that a more complex approach should be used in order to make the decision. In fact, this case study defines a typical multi-dimensional criteria decision-making problem. The main difficulty of this case study is the value of $\mathrm{CO}_{2}$ emissions criterion, which is negative for both $\mathrm{XL}$ and $\mathrm{XZ}$ wind turbines for production level value of $60 \%$, is positive for $\mathrm{XL}$ wind turbine and negative for $\mathrm{XZ}$ wind turbine for production level range of $70 \div 80 \%$, and finally, is positive for both $\mathrm{XL}$ and $\mathrm{XZ}$ wind turbines for production level range of $80 \div 100 \%$, Figure 7 . Solving this complex situation will be done using the TOPSIS method [5], which consists in the following main steps:

- Establishing the decision matrix. Let us consider $n$ alternatives $A_{j}, \mathrm{j}=1 \div \mathrm{n}$ which are evaluated for m criteria $C_{i}, \quad \mathrm{i}=1 \div \mathrm{m}$. The decision matrix consists in the performance ratings $x_{i j}$ of $i$-th criterion with respect to the $\mathrm{j}$-th alternative and is presented in Table 1.

Table 1. Decision matrix.

\begin{tabular}{|c|c|c|c|c|c|c|}
\hline \multirow{2}{*}{$\begin{array}{c}\text { Decision } \\
\text { matrix }\end{array}$} & \multicolumn{6}{|c|}{ Alternatives } \\
\cline { 2 - 7 } & $A_{1}$ & $A_{2}$ & $\ldots$ & $A_{j}$ & $\ldots$ & $A_{n}$ \\
\hline$U=C_{1}$ & $x_{11}$ & $x_{12}$ & $\ldots$ & $x_{1 j}$ & $\ldots$ & $x_{1 n}$ \\
\hline
\end{tabular}

\begin{tabular}{|c|c|c|c|l|c|c|c|}
\hline \multirow{7}{*}{$C_{2}$} & $x_{21}$ & $x_{22}$ & & $x_{2 j}$ & & $x_{2 n}$ \\
\cline { 2 - 7 } & $\vdots$ & $\vdots$ & $\vdots$ & & $\vdots$ & & $\vdots$ \\
\cline { 2 - 7 } & $C_{i}$ & $x_{i 1}$ & $x_{i 2}$ & $\ldots$ & $x_{i j}$ & $\ldots$ & $x_{i n}$ \\
\hline$\vdots$ & $\vdots$ & $\vdots$ & & $\vdots$ & & $\vdots$ \\
\hline & $C_{m}$ & $x_{m 1}$ & $x_{m 2}$ & $\ldots$ & $x_{m j}$ & $\ldots$ & $x_{m n}$ \\
\hline
\end{tabular}

- Calculate the normalized decision matrix:

$$
r_{i j}=\frac{x_{i j}}{\sqrt{\sum_{j=1}^{n} x_{i j}^{2}}}
$$

- Establishing the weights $W_{i}$ and computing the normalized weights $w_{i}$ of the criteria $C_{i}$, where $\mathrm{i}=1 \div \mathrm{m}$ and $\sum_{i=1}^{m} w_{i}=1$ :

$$
w_{i}=\frac{W_{i}}{\sum_{i=1}^{m} W_{i}}
$$

- Calculate the weighted normalized decision matrix:

$$
v_{i j}=w_{i} \cdot r_{i j}
$$

- Identify the ideal solution $\left(A^{+}\right)$and the negative ideal solution $\left(A^{-}\right)$:

$$
\begin{aligned}
A^{+} & =\left\{v_{l}^{+}, v_{2}^{+}, \ldots, v_{i}^{+}, \ldots, v_{n}^{+}\right\} \\
A^{-} & =\left\{v_{l}^{-}, v_{2}^{-}, \ldots, v_{i}^{-}, \ldots, v_{n}^{-}\right\}
\end{aligned}
$$

where $v_{i}^{+}$and $v_{i}^{-}$are the best value, respectively the worst value for the $i$-th criterion among all alternatives.

- Calculate the n-dimensional Euclidean distance between each alternative and the ideal solution:

$$
D_{j}^{+}=\sqrt{\sum_{i=1}^{m}\left(v_{i j}-v_{i}^{+}\right)^{2}}, j=1 \div n
$$

- Calculate the n-dimensional Euclidean distance between each alternative and the negative ideal solution:

$$
D_{j}^{-}=\sqrt{\sum_{i=1}^{m}\left(v_{i j}-v_{i}^{-}\right)^{2}}, j=1 \div n
$$

- Calculate the ranking score (the relative closeness to the ideal solution):

$$
R_{j}=\frac{D_{j}^{-}}{D_{j}^{+}+D_{j}^{-}}, \quad j=1 \div n
$$

The preference order of the alternatives can be obtained by sorting the ranking scores in descending order, the best alternative having the maximum ranking score. 


\section{Methodology}

The principal steps of applying the TOPSIS method for this case study are:

- $\quad$ Selecting the criteria for finding the most suitable wind turbine. These criteria are $\mathrm{T} 1 \div \mathrm{T} 5, \mathrm{~F} 1 \div \mathrm{F} 4$, and $\mathrm{E} 1$.

- $\quad$ Selecting the alternatives to be evaluated. There are two alternatives, $\mathrm{XZ}$ and $\mathrm{XL}$.

- $\quad$ Score each criterion of each alternative. The raw scores represent the performance ratings $\left(x_{i j}\right)$ and will be used for filling the decision matrix. The raw scores come from HOMER simulations. As we mention before, the HOMER project file will be calculated for all five values of production level $(60,70,80,90$ and 100\%), as consequence, five sets of raw scores and five decision matrices will be obtained. The negative values of $\mathrm{CO}_{2}$ emissions, that have been already noticed, qualitatively, in Figure 7, can be also quantitatively expressed by: $4.766 \mathrm{t} /$ year and $-2.185 \mathrm{t} /$ year for $\mathrm{XZ}$ and XL wind turbines for $60 \%$ production level, Table $2 ;-2.459 \mathrm{t} /$ year and $0.122 \mathrm{t} /$ year for $\mathrm{XZ}$ and XL wind turbines for $70 \%$ production level, Table 3; -0.152 t/year and $2.428 \mathrm{t} /$ year for $\mathrm{XZ}$ and $\mathrm{XL}$ wind turbines for $80 \%$ production level, Table 4. For production levels $90 \%$ and $100 \%$ there are no negative values for $\mathrm{CO}_{2}$ emissions.

Table 2. Decision matrix for $60 \%$ production level.

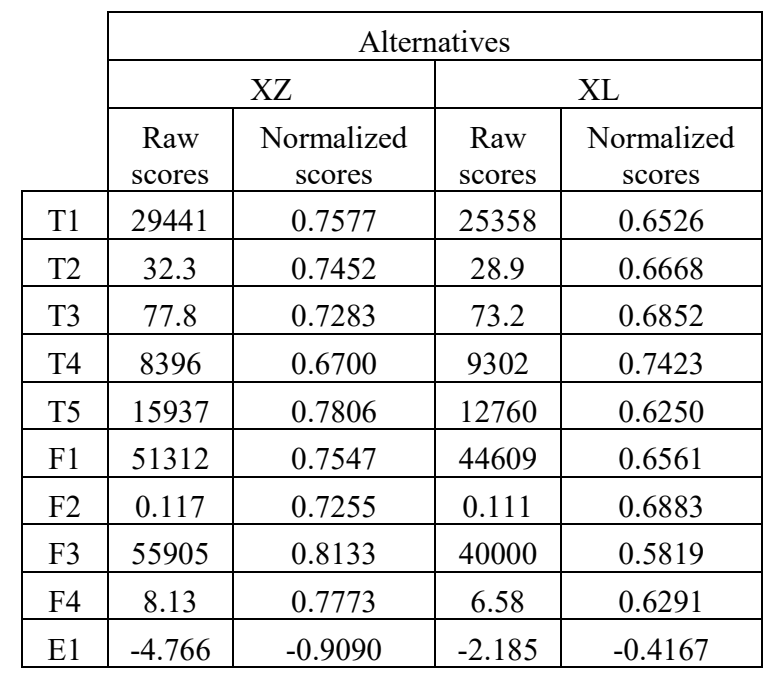

Table 3. Decision matrix for $70 \%$ production level.

\begin{tabular}{|c|c|c|c|c|}
\cline { 2 - 5 } \multicolumn{1}{c|}{} & \multicolumn{3}{c|}{ Xlternatives } \\
\cline { 2 - 5 } \multicolumn{1}{c|}{} & \multicolumn{2}{c|}{ XZ } & \multicolumn{2}{c|}{ XL } \\
\cline { 2 - 5 } & $\begin{array}{c}\text { Raw } \\
\text { scores }\end{array}$ & $\begin{array}{c}\text { Normalized } \\
\text { scores }\end{array}$ & $\begin{array}{c}\text { Raw } \\
\text { scores }\end{array}$ & $\begin{array}{c}\text { Normalized } \\
\text { scores }\end{array}$ \\
\hline T1 & 29441 & 0.7577 & 25358 & 0.6526 \\
\hline T2 & 32.3 & 0.7452 & 28.9 & 0.6668 \\
\hline T3 & 73.7 & 0.7325 & 68.5 & 0.6808 \\
\hline T4 & 10499 & 0.6699 & 11637 & 0.7425 \\
\hline T5 & 14390 & 0.7826 & 11445 & 0.6225 \\
\hline F1 & 62382 & 0.7448 & 55894 & 0.6673 \\
\hline F2 & 0.135 & 0.7203 & 0.13 & 0.6936 \\
\hline F3 & 55905 & 0.8133 & 40000 & 0.5819 \\
\hline F4 & 7.99 & 0.7772 & 6.47 & 0.6293 \\
\hline E1 & -2.459 & -0.9988 & 0.122 & 0.0496 \\
\hline
\end{tabular}

Table 4. Decision matrix for $80 \%$ production level.

\begin{tabular}{|c|c|c|c|c|}
\cline { 2 - 5 } \multicolumn{1}{c|}{} & \multicolumn{4}{c|}{ Alternatives } \\
\cline { 2 - 5 } \multicolumn{1}{c|}{} & \multicolumn{2}{c|}{ XZ } & \multicolumn{2}{c|}{ XL } \\
\cline { 2 - 5 } \multicolumn{1}{c|}{$\begin{array}{c}\text { Raw } \\
\text { scores }\end{array}$} & $\begin{array}{c}\text { Normalized } \\
\text { scores }\end{array}$ & $\begin{array}{c}\text { Raw } \\
\text { scores }\end{array}$ & $\begin{array}{c}\text { Normalized } \\
\text { scores }\end{array}$ \\
\hline T1 & 29441 & 0.7577 & 25358 & 0.6526 \\
\hline T2 & 32.3 & 0.7452 & 28.9 & 0.6668 \\
\hline T3 & 69.8 & 0.7355 & 64.3 & 0.6775 \\
\hline T4 & 12721 & 0.6699 & 14099 & 0.7425 \\
\hline T5 & 12962 & 0.7842 & 10257 & 0.6205 \\
\hline F1 & 73562 & 0.7378 & 67296 & 0.6750 \\
\hline F2 & 0.151 & 0.7165 & 0.147 & 0.6976 \\
\hline F3 & 55905 & 0.8133 & 40000 & 0.5819 \\
\hline F4 & 7.96 & 0.7769 & 6.37 & 0.6296 \\
\hline E1 & -0.152 & -0.0625 & 2.428 & 0.9980 \\
\hline
\end{tabular}

- Using formula (2), the raw scores will be normalized, obtaining the normalized scores presented for $60 \%, 70 \%$ and $80 \%$ in Tables 2, 3 and 4.

- Weighting the criteria to reflect their relative importance to the decision. Weights $\left(W_{i} \in \mathrm{N}\right)$ have been obtained by subjective direct assignation on a preference scale within the range $1 \div \mathrm{m}$, where 1 correspond with the least preferred option and $m$ correspond with the most preferred option. Weighting the criteria is made according with the project strategy. For example, one possible strategy can be expressed by: the most preferred is the environmental criterion (E), the least preferred are the financial criteria $(\mathrm{F})$, while the technical criteria are between the environmental and the financial criteria, defining thus the strategy S1-ETF. In this paper eleven strategies will be presented, $\mathrm{S} 1 \div \mathrm{S} 5$ based on $\mathrm{T}, \mathrm{F}$ and $\mathrm{E}$ criteria; S6 and S7 based only on T and F criteria; S8 and S9 based only on F and E criteria; S10 and S11 based only on $\mathrm{T}$ and $\mathrm{E}$ criteria.

- $\quad$ Computing the normalized weights $w_{i}$ with (3).

- Computing the weighted normalized decision matrix $v_{i j}$ with (4).

- $\quad$ Identifying the ideal solution $\left(A^{+}\right)$and the negative ideal solution $\left(A^{-}\right)$with (5) and (6).

- $\quad$ Computing the n-dimensional Euclidean distance between each alternative and the ideal solution $D_{j}^{+}$, as well as between each alternative and the negative ideal solution $D_{j}^{-}$with (7) and (8).

- $\quad$ Computing the ranking score $R_{j}$ with (9).

- $\quad$ Ranking the alternatives according with the ranking scores.

\section{Weighting strategies based on T, F and $E$ criteria}

For this case, five weighting strategies have been considered: S1-ETF, S2-TEF, S3-EFT, S4-FET, and S5FTE, Table 5. 
Table 5. Weighting strategies for $\mathrm{T}, \mathrm{F}$ and $\mathrm{E}$ criteria.

\begin{tabular}{|c|c|c|c|c|c|c|}
\hline \multirow{2}{*}{\multicolumn{2}{|c|}{$\begin{array}{c}\text { Weights } \\
W_{i}\end{array}$}} & \multicolumn{5}{|c|}{ Strategy } \\
\hline & & S1 & S2 & S3 & S4 & S5 \\
\hline \multirow{10}{*}{ 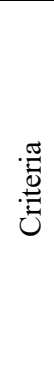 } & $\mathrm{T} 1$ & 9 & 10 & 5 & 5 & 6 \\
\hline & $\mathrm{T} 2$ & 8 & 9 & 4 & 4 & 5 \\
\hline & T3 & 7 & 8 & 3 & 3 & 4 \\
\hline & $\mathrm{T} 4$ & 6 & 7 & 2 & 2 & 3 \\
\hline & T5 & 5 & 6 & 1 & 1 & 2 \\
\hline & F1 & 4 & 4 & 9 & 10 & 10 \\
\hline & $\mathrm{F} 2$ & 3 & 3 & 8 & 9 & 9 \\
\hline & F3 & 2 & 2 & 7 & 8 & 8 \\
\hline & F4 & 1 & 1 & 6 & 7 & 7 \\
\hline & E1 & 10 & 5 & 10 & 6 & 1 \\
\hline
\end{tabular}

Starting with the decision matrices for all production levels, using the weighting strategies $\mathrm{S} 1 \div \mathrm{S} 5$ and applying the TOPSIS method algorithm the following results have been obtained:

- the comparative analysis of the ranking scores for XZ (Figure 12) and XL (Figure 13) wind turbines with respect to the weighting strategies $\mathrm{S} 1 \div \mathrm{S} 5$;

- the comparative analysis of the ranking scores for S1 (Figure 14), S2 (Figure 15), S3 (Figure 16), S4 (Figure 17) and S5 (Figure 18) weighting strategies with respect to the wind turbines $\mathrm{XZ}$ and $\mathrm{XL}$.

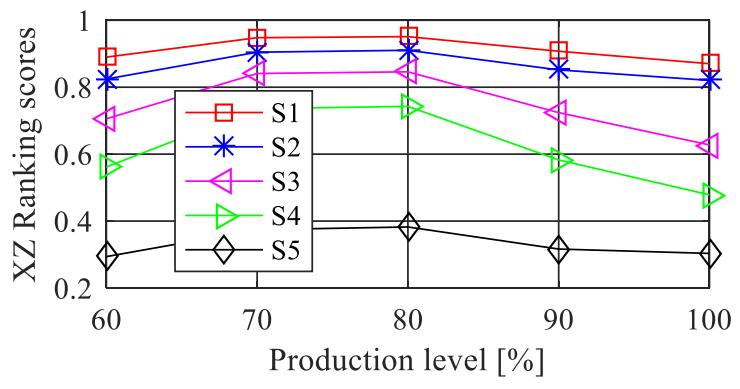

Fig. 12. Ranking scores for $\mathrm{XZ}$ wind turbine.

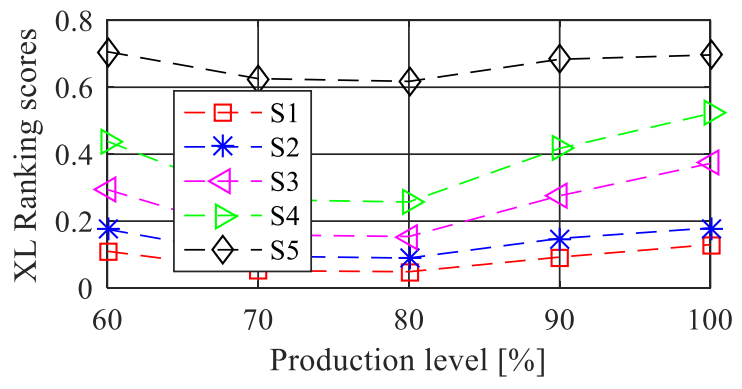

Fig. 13. Ranking scores for $X L$ wind turbine.

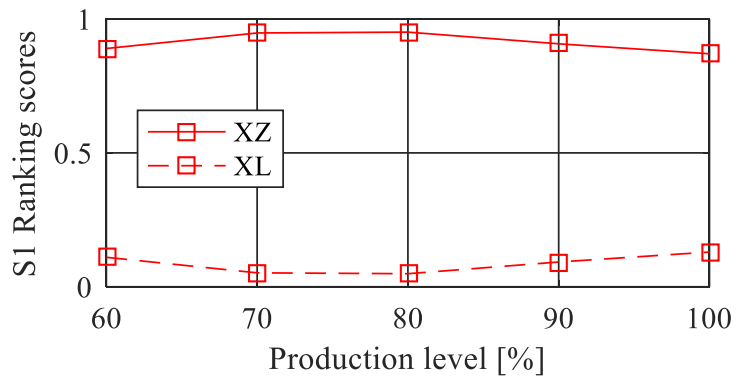

Fig. 14. Ranking scores for $S 1$ weighting strategy.

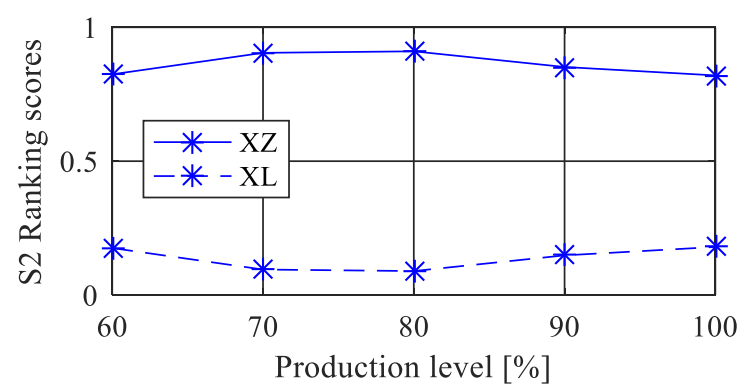

Fig. 15. Ranking scores for $S 2$ weighting strategy.

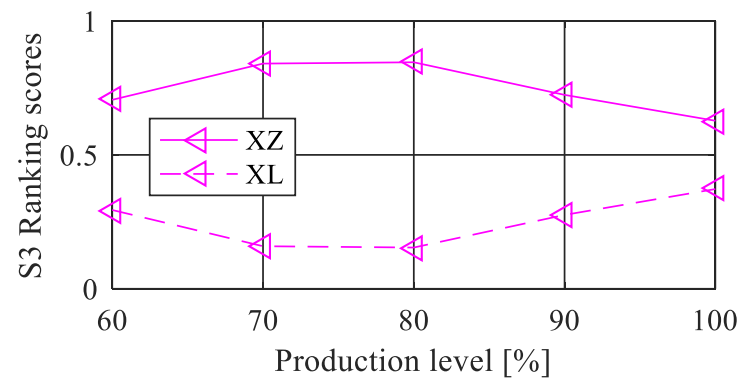

Fig. 16. Ranking scores for S3 weighting strategy.

For all weighting strategies the ranking scores will have extreme values for $70 \%$ and $80 \%$ production levels; however, these extreme values are maximum values for $\mathrm{XZ}$ wind turbine (Figure 12), and minimum values for XL wind turbines (figure 13).

For weighting strategies S1 (Figure 14), S2 (Figure 15) and S3 (Figure 16), and for all production levels $60 \div 100 \%$, the ranking scores of $\mathrm{XZ}$ wind turbine are greater than the ranking scores of $\mathrm{XL}$ wind turbine.

The difference between ranking scores is maximum for S1 strategy, and decreases to S2 strategy, being at minimum levels for S3 strategy. With respect to the production levels, for the range $70 \div 80 \%$, the difference between the ranking scores of the alternatives are at maximum levels. Thus, it is clear that for these three strategies (S1, S2 and S3), the decision is that the $\mathrm{XZ}$ wind turbine alternative is more suitable than the $\mathrm{XL}$ wind turbine alternative, for all production levels, but even more so for inside the range $70 \div 80 \%$.

A situation less clear can be observed for the S4 weighting strategy (Figure 17). In this case, the ranking scores of $\mathrm{XZ}$ wind turbine are greater than the ranking scores of XL wind turbine, but only for production levels between $60 \%$ and $\cong 98 \%$. For production level between $98 \%$ and $100 \%$, the ranking scores of XL wind turbine are greater than the ranking scores of $\mathrm{XZ}$ wind turbine. For $100 \%$ production level the ranking scores are 0.4784 for $\mathrm{XZ}$ wind turbine and 0.5215 for XL wind turbine. If the $\mathrm{XZ}$ wind turbine will be chosen, even if the ranking score indicates the other alternative, the relative error of this decision will be $8.26 \%$. Thus, for S4 strategy, the decision is that $\mathrm{XZ}$ wind turbine alternative is more suitable than the $\mathrm{XL}$ wind turbine alternative, without no doubt for production levels inside the range $60 \div 98 \%$, while for the production level range $98 \div 100 \%$ the relative error of this decision being maximum $8.26 \%$. 


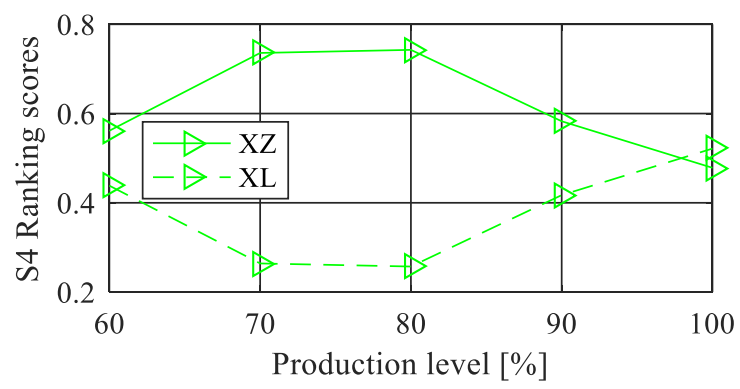

Fig. 17. Ranking scores for S4 weighting strategy.

For S5 weighting strategy (Figure 18), and for all production levels $60 \div 100 \%$, the ranking scores of $\mathrm{XL}$ wind turbine are greater than the ranking scores of $\mathrm{XZ}$ wind turbine. With respect to the production levels, for the range $70 \div 80 \%$, the difference between the ranking scores of the alternatives are at minimum levels. Thus, it is clear that for the S5 strategy, the decision is that the XL wind turbine alternative is more suitable than the $\mathrm{XZ}$ wind turbine alternative, for all production levels, but even more so for outside the range $70 \div 80 \%$.

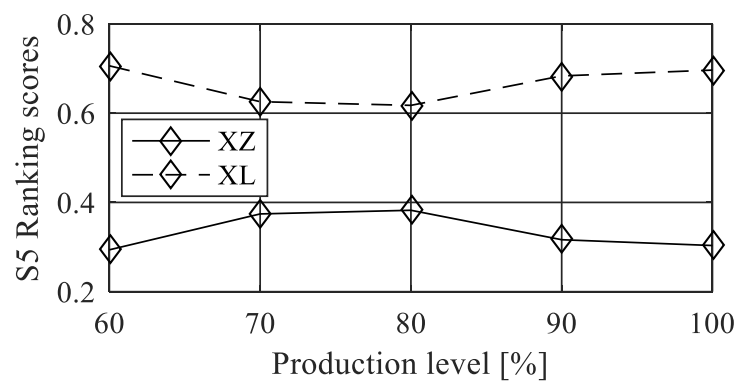

Fig. 18. Ranking scores for S5 weighting strategy.

\section{Weighting strategies based only on $\mathrm{T}$ and $F$ criteria}

The environmental criterion $\left(\mathrm{CO}_{2}\right.$ emissions) generates, as has been mentioned before, the negative values situation. What if this criterion will be eliminated from the analysis, and only technical and financial criteria will be used? Analysing the strategy table presented in Table 5, but without E1 criterion, two more strategies can be defined: S6-TF and S7-FT, Table 6.

Table 6. Weighting strategies for $\mathrm{T}$ and $\mathrm{F}$ criteria.

\begin{tabular}{|c|c|c|c|}
\hline \multirow{2}{*}{\multicolumn{2}{|c|}{$\begin{array}{c}\text { Weights } \\
W_{i}\end{array}$}} & \multicolumn{2}{|c|}{ Strategy } \\
\hline & & S6 & S7 \\
\hline \multirow{9}{*}{ 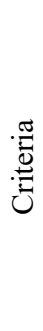 } & T1 & 9 & 5 \\
\hline & $\mathrm{T} 2$ & 8 & 4 \\
\hline & T3 & 7 & 3 \\
\hline & $\mathrm{T} 4$ & 6 & 2 \\
\hline & T5 & 5 & 1 \\
\hline & F1 & 4 & 9 \\
\hline & F2 & 3 & 8 \\
\hline & F3 & 2 & 7 \\
\hline & $\mathrm{F} 4$ & 1 & 6 \\
\hline
\end{tabular}

The comparative analysis of the ranking scores for S6 and S7 weighting strategies with respect to the wind turbines $\mathrm{XZ}$ and $\mathrm{XL}$ is presented in Figure 19 (S6) and Figure 20 (S7).

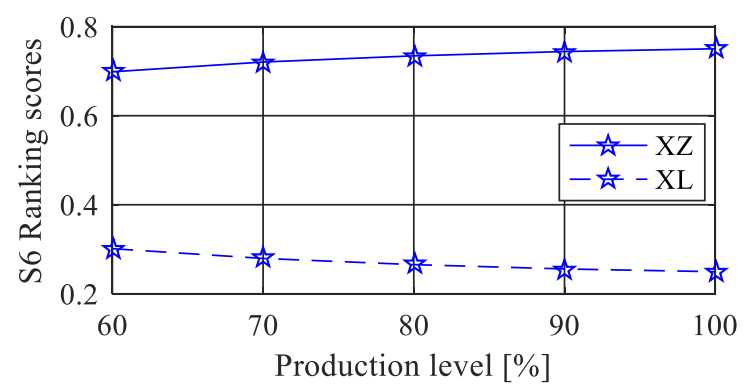

Fig. 19. Ranking scores for S6 weighting strategy.

For weighting strategy S6 (Figure 19), and for all production levels $60 \div 100 \%$, the ranking scores of $\mathrm{XZ}$ wind turbine are greater than the ranking scores of $\mathrm{XL}$ wind turbine. The difference between ranking scores increases with production level. Thus, it is clear that for the $\mathrm{S} 6$ strategy, the decision is that the $\mathrm{XZ}$ wind turbine alternative is more suitable than the $\mathrm{XL}$ wind turbine alternative, for all production levels, but even more so for higher production levels.

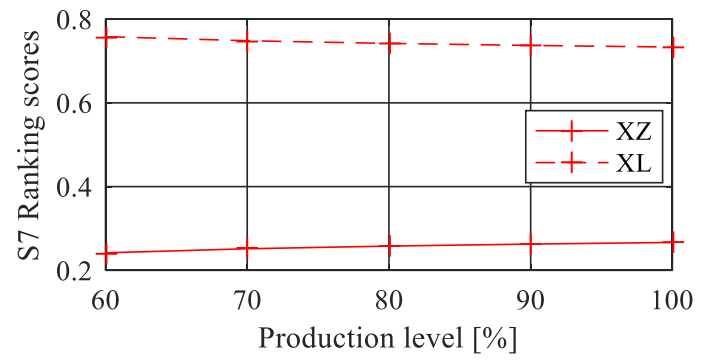

Fig. 20. Ranking scores for S7 weighting strategy.

For weighting strategy S7 (Figure 20), and for all production levels $60 \div 100 \%$, the ranking scores of XL wind turbine are greater than the ranking scores of $\mathrm{XZ}$ wind turbine. The difference between ranking scores decreases with production level. Thus, it is clear that for the S7 strategy, the decision is that the XL wind turbine alternative is more suitable than the $\mathrm{XZ}$ wind turbine alternative, for all production levels, but even more so for lower production levels.

\section{Weighting strategies based only on $F$ and $\mathrm{E}$ criteria}

Analysing the strategy table presented in Table 5, but without $\mathrm{T}$ criteria, two more strategies can be defined: $\mathrm{S} 8$ EF and S9-FE, Table 7.

Table 7. Weighting strategies for $\mathrm{F}$ and $\mathrm{E}$ criteria.

\begin{tabular}{|c|c|c|c|}
\hline \multirow{2}{*}{\multicolumn{2}{|c|}{$\begin{array}{c}\text { Weights } \\
W_{i}\end{array}$}} & \multicolumn{2}{|c|}{ Strategy } \\
\hline & & S8 & S9 \\
\hline \multirow{5}{*}{ 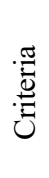 } & F1 & 4 & 5 \\
\hline & F2 & 3 & 4 \\
\hline & F3 & 2 & 3 \\
\hline & $\mathrm{F} 4$ & 1 & 2 \\
\hline & E1 & 5 & 1 \\
\hline
\end{tabular}


The comparative analysis of the ranking scores for S8 and S9 weighting strategies with respect to the wind turbines $\mathrm{XZ}$ and $\mathrm{XL}$ is presented in Figure 21 (S8) and Figure 22 (S9).

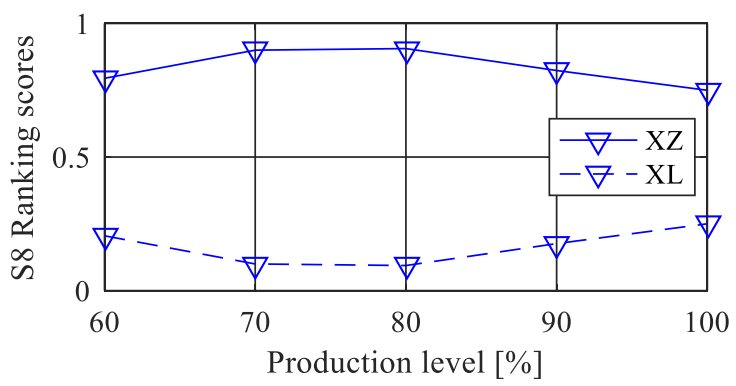

Fig. 21. Ranking scores for S8 weighting strategy.

For weighting strategy S8 (Figure 21), and for all production levels $60 \div 100 \%$, the ranking scores of $\mathrm{XZ}$ wind turbine are greater than the ranking scores of XL wind turbine. Thus, it is clear that for the S8 strategy, the decision is that the $\mathrm{XZ}$ wind turbine alternative is more suitable than the XL wind turbine alternative, for all production levels.

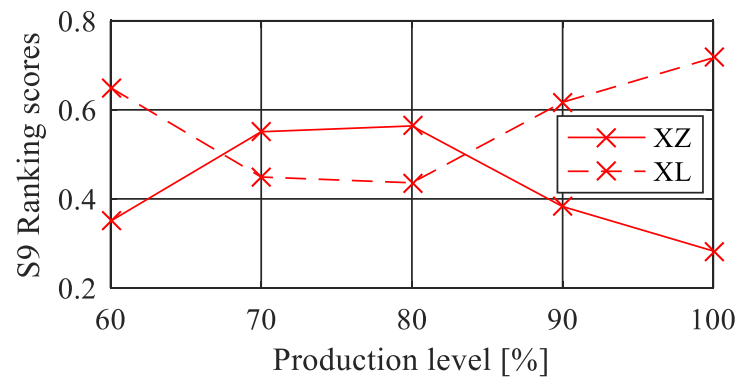

Fig. 22. Ranking scores for S9 weighting strategy.

For weighting strategy S9 (Figure 22), the ranking scores of $\mathrm{XZ}$ wind turbine are greater than the ranking scores of XL wind turbine only for production levels in range $67.5 \div 83.5 \%$. In this case cannot be made any clear decision.

\section{Weighting strategies based only on T and E criteria}

Analysing the strategy table presented in Table 5, but without $\mathrm{F}$ criteria, two more strategies can be defined: S10-TE and S11-ET, Table 8.

Table 8. Weighting strategies for $\mathrm{T}$ and $\mathrm{E}$ criteria.

\begin{tabular}{|c|c|c|c|}
\hline \multirow{2}{*}{\multicolumn{2}{|c|}{$\begin{array}{c}\text { Weights } \\
W_{i}\end{array}$}} & \multicolumn{2}{|c|}{ Strategy } \\
\hline & & $\mathrm{S} 10$ & S11 \\
\hline \multirow{6}{*}{ 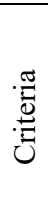 } & $\mathrm{T} 1$ & 6 & 5 \\
\hline & $\mathrm{T} 2$ & 5 & 4 \\
\hline & $\mathrm{T} 3$ & 4 & 3 \\
\hline & $\mathrm{T} 4$ & 3 & 2 \\
\hline & T5 & 2 & 1 \\
\hline & E1 & 1 & 6 \\
\hline
\end{tabular}

For these particular weighting strategies, an interesting result has been obtained: the ranking scores of $\mathrm{XZ}$ wind turbine is 1 , while the ranking score of the $\mathrm{XL}$ wind turbine is 0 , for all production levels. This means that the most suitable alternative coincides with the ideal solution, while the other alternative coincides with the negative ideal solution.

\section{Conclusions}

For a given decision matrix, the weighting strategy of the criteria is extremely important, and may change radically the final decision. Considering T, F and E criteria, it is possible to make a clear decision for all 5 considered weighting strategies: XZ wind turbine for S1, S2, S3 and S4 (for S4 with maximum $8.26 \%$ error for $98 \div 100 \%$ production levels), and XL wind turbine for S5.

Considering only $\mathrm{T}$ and $\mathrm{F}$ criteria, it is also possible to make a clear decision for both S6 and S7 weighting strategies: XZ wind turbine for S6, and XL wind turbine for S7. Considering only $\mathrm{E}$ and $\mathrm{F}$ criteria it is possible to make a clear decision only for S8 weighting strategy: XZ wind turbine. For S9 weighting strategy it is impossible to make a clear decision. Considering only $\mathrm{T}$ and $\mathrm{E}$ criteria, it is also possible to decide: $\mathrm{XZ}$ wind turbine for both $\mathrm{S} 10$, and S11 weighted strategies. Moreover, this is a special case where the $\mathrm{XZ}$ wind turbine is identical with the ideal solution, while the other alternative, XL wind turbine, is identical with the negative ideal solution. From all weighting strategies considered in this case study, the XZ wind turbine has been selected for 8 strategies and the XL wind turbine has been selected for 2 strategies.

As regards the negative performance ratings, the key element that allows to use the TOPSIS method is the concept of n-dimensional Euclidean distance between each alternative and the ideal solution, respectively the negative ideal solution.

The authors would like to acknowledge the technical resources offered by the Laboratory of Computer-Aided Fluid Engineering, from the Department of Fluid Mechanics, Fluid Machinery and Fluid Power Systems, "Gheorghe Asachi" Technical University of Iasi, Romania. The Laboratory of Computer-Aided Fluid Engineering has been equipped with technical resources with the financial support of the grant ENERED, POSCCE-A2-O2.2.1-2009-4, ID 911.

\section{References}

1. L. Sagbansua, F. Balo, Procedia Comput. Sci. 111, 413 (2017)

2. S. Rehman, S.A. Khan, Int. J. of Adv. Comp. Sci. and Apps. 8, 128 (2017)

3. A.H.I. Lee, M.C. Hung, H.Y, Kang, W.L. Pearn, Energ. Convers. Manage. 64, 289 (2012)

4. J.J. Wang, Y.Y. Jing, C.F. Zhang, J.H. Zhao, 2009 Renew. Sust. Energ. Rev. 13, 2263 (2009)

5. G.H. Tzeng, J.J. Huang, Multiple Attribute Decision Making. Methods and Applications (CRC Press, 2011)

6. D. Zahariea., C.M. Husaru, D.E. Husaru, IOP Conf. 
S.: Mat. Sci. Eng. (to be published)

7. HOMER Energy, The HOMER Pro microgrid software, https://www.homerenergy.com/index.html, accessed at 15.05.2018

8. XZERES, 2017, XZERES 442SR Wind Turbines http://www.xzeres.com/wind-turbine-products/ xzeres-442sr-small-wind-turbine/, accessed at 6.06 .2018

9. Bergey, 2017, The Excel $10 \mathrm{~kW}$ Wind Turbine, http://bergey.com/products/wind-turbines/10kwbergey-excel, accessed at 2.06.2018

10. NASA Atmospheric Science Data Centre, Surface Meteorology and Solar Energy Database, https://eosweb.larc.nasa.gov/cgi-bin/sse/sse.cgi, accessed at 6.06.2018

11. European Commission, EUROSTAT, Electricity prices for non-household consumers, http://appsso. eurostat.ec.europa.eu/nui/submitViewTableAction.d o, accessed at 6.06.2018

12. World Bank Group, State and Trends of Carbon Pricing 2017, http://documents.worldbank.org/ curated/en/468881509601753549/State-and-trendsof-carbon-pricing-2017, accessed at 6.06.2018 